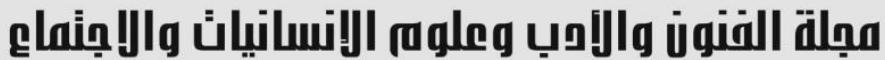

Journal of Arts, Literature, Humanities and Social Sciences www.jalhss.com

\section{مظاهز التطور الفكري للمجتمع الأوروبي بعد عصر النهضة وحتى عام 1845م الاورئم}

نوران محمد أحمد السيا باز قسم التاريخ ـ كلية البنات للآداب والعلوم والتربية - جامعة عين شمس - مصر الايميل: noranmab9@gmail.com

الملخص

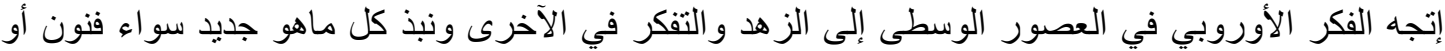

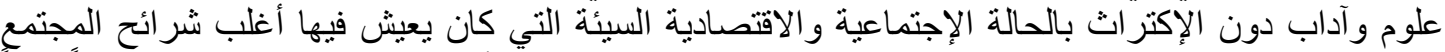

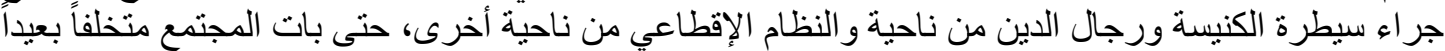

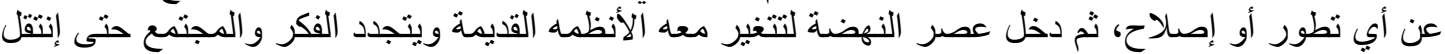

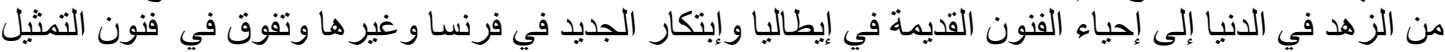

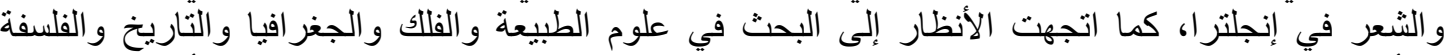

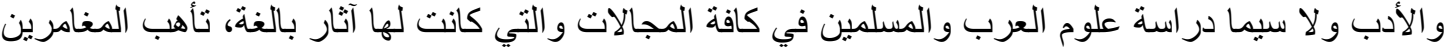

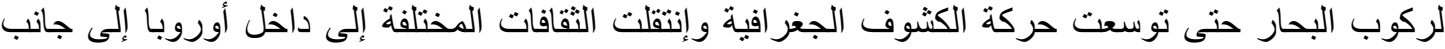

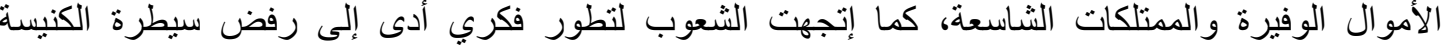

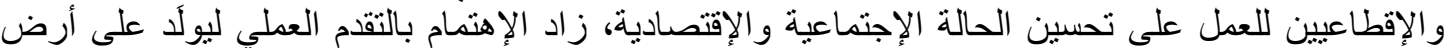

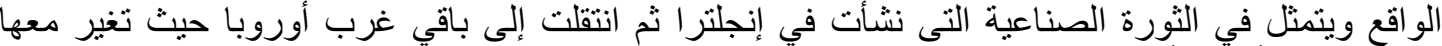

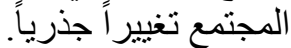

بدأ هذا التطور بالنمو الفكري أولاً ورفض السكون الذي كان من سمات العصور الوسطى فكان بداية لتقدم

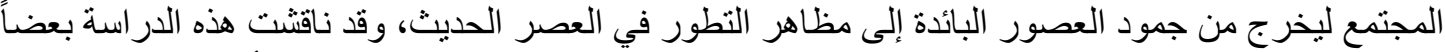
منها تمثلت في: الكثوف الجغر افية، الإصلاح الكنسي (البروتستانتي)، و الثورة الصناعية (الأولى). 


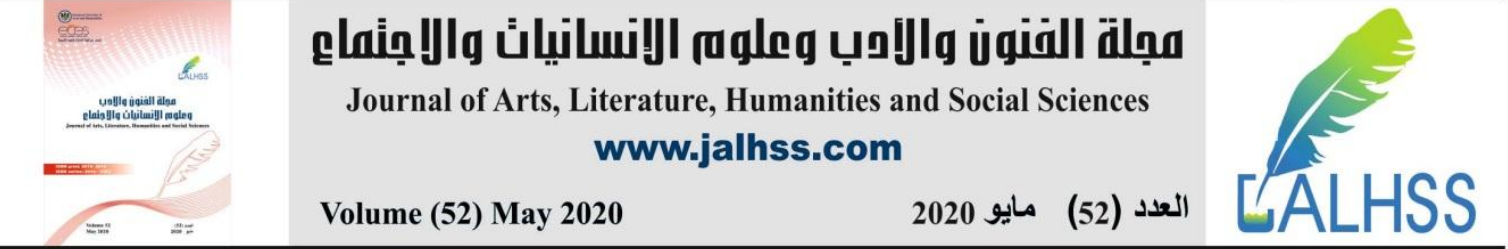 \\ Manifestations of Intellectual Development of European Society after the Renaissance Until 1845 AD
}

\author{
Noran Mohamed Ahmed El Saied Baz \\ History Department - Faculty of Women For Arts, Science and Education - Ain \\ Shams University - Egypt \\ Email: noranmab9@gmail.com
}

\begin{abstract}
European thought in the Middle Ages tended to denounce and contemplate the other and reject everything new, whether arts, sciences and literature without regard to the bad economic and economic situation in which the segments of society were due to the domination of the Church by men and the feudal system on the other hand, until society became backward from any Evolution or repair, It entered the Renaissance to change with him the old systems and renewed European thought and society until he moved from the low in the world to the revival of the ancient arts in Italy and the innovation of the new in France and others and the superiority of the arts of acting and poetry in England, Attention also turned to research in the sciences of nature, astronomy, geography, history, philosophy and literature, especially transportation of great importance from the sciences of Arabs and Muslims in all fields. The adventurers prepared to ride the seas until the movement of geographical expansions expanded and the different cultures moved into Europe, especially the abundant funds and properties, the peoples turned to develop My thinking led to the refusal of the Church and the feudal lords to work to improve the social and economic situation, Increased interest in practical progress was born on the ground, represented in the industrial revolution that arose in England and then moved to the rest of Europe, where its attributes changed society radically.
\end{abstract}

This development began with an intellectual change first and rejected the stillness that was a feature of the middle Ages. It was the beginning of the progress of society to move from the immobility of the ancient ages to the manifestations of development in the modern era.

Keywords: Intellectual development, European society, Renaissance. 


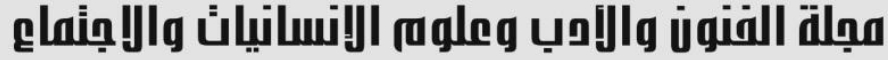

Journal of Arts, Literature, Humanities and Social Sciences

www.jalhss.com

Volume (52) May 2020

العدد (52) مايو 2020

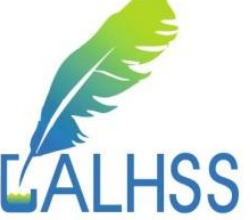

المقدمة

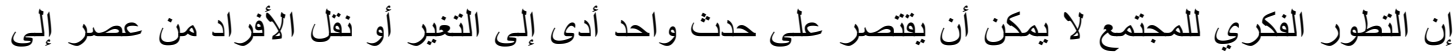

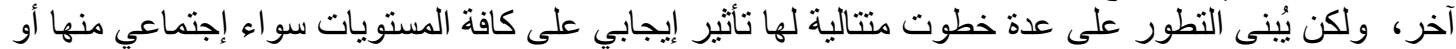

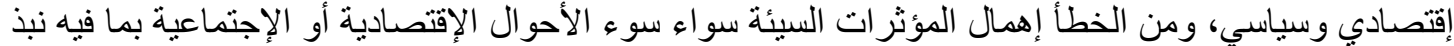

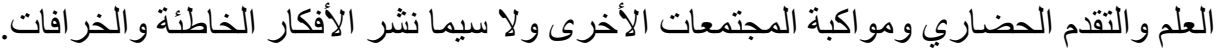

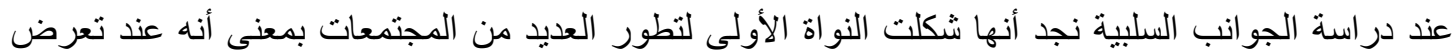

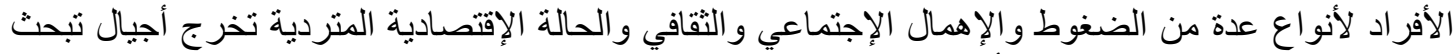

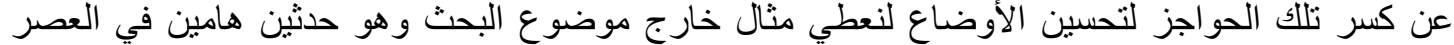

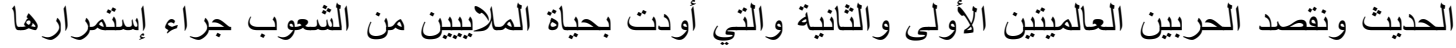

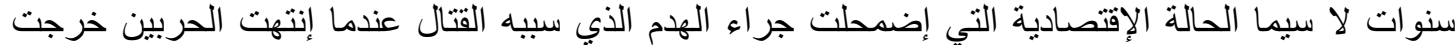

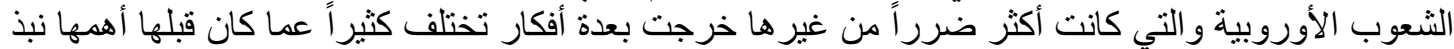

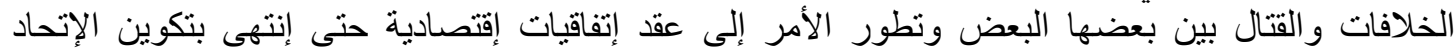

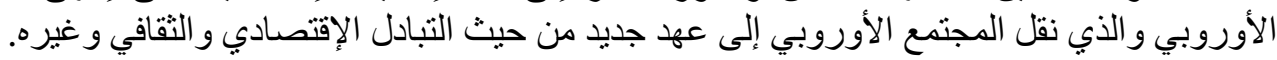

و هنا يأتي أهمية البحث في نفس الغرض و هي الضغوضات التي مارستها الكنبسة والأنظمة الإقطاعية و غيرها

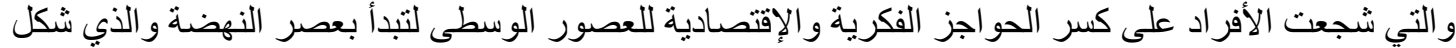
معاه مجتمع أوروبي تعددت مظاهر تطوره الأن الفكري.

التمهيد

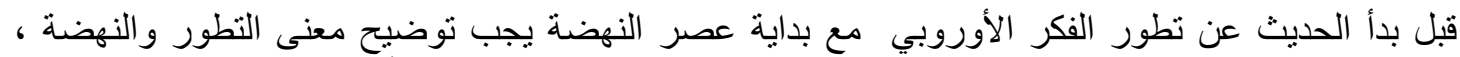

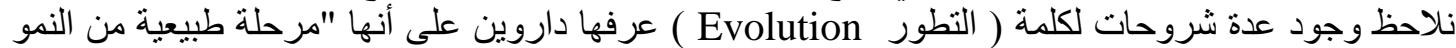

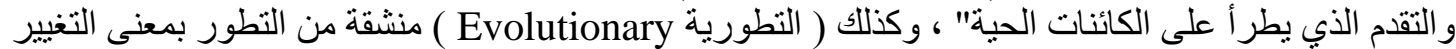
في نمط الحياة والأشياء والتقدم في النظم سواء الفكري منها أو التعلميمي أو غيره (الكيالي عبد الوهاب، 1979،

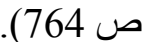

أما معنى النهضة فهو التطور في الآداب و العلوم و الفنون إلى جانب تغير في أسس الحياة الإقتصادية والإجتماعية و السياسية لذلك أطلق عصر النهضة على الإنتقال من العصور الوسطى إلى العصور العيلى الحديثة.

بدأت النهضة في إيطاليا ثم إنتقلت إلى فرنسا، إنجلترا، أسبانيا وسويسرا وباقي بقاع أوروبا الغربية، ولكنها

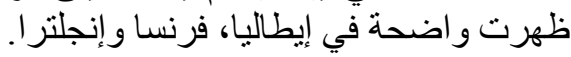

وقد إثتهر كلاً منهم بعو امل النهضة الخاصة به سواء في الفنون أو الفلسفة والأدب أو الكتابة و الثعر و العلوم.

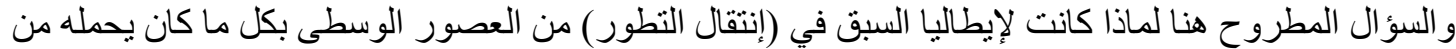

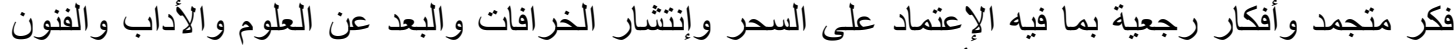

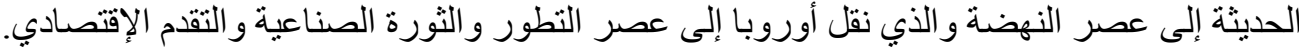

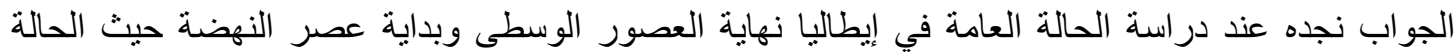
المادية الجيدة والرخاء الإقتصادي، فقد شهدت المدن الإيطالية إنتعاش إقتصادي مقارنة بباقي عو الصم أوروبا.

يرجع السبب في ذلك لربحها من التجارة بين الثرق والغرب ومن أهم تللك المدن البندقية، جنوة وميلان وقد

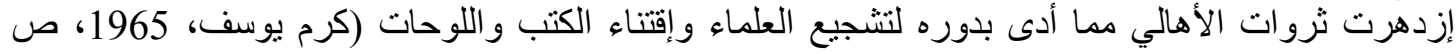




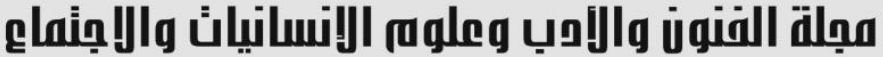

Journal of Arts, Literature, Humanities and Social Sciences www.jalhss.com

جدير بالذكر أن التجارة سواء بحرية منها أو برية لا تدر على المدن التي تمر عليها رخاء إقتصادي فقط ولكنها

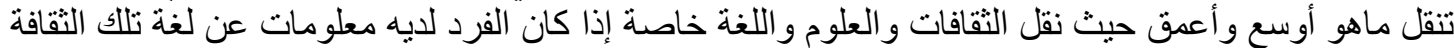
مما يعمل على توسيع الأفاق و البحث في مناحي مختلفة من العلم و المعرفة.

ميزة أخرى جعلت المدن الإيطالية تحظى بالسبق في النهضة وهي وجود المقر الباباوي حيث أعطى لإيطاليا

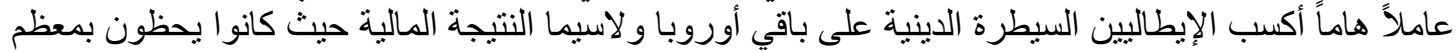
الوظائف الكنسية ويتقاضون رواتئ التب عالية.

و بالر غم من أن السلطة الدينية في العصور الوسطى كانت تحول بين الأشخاص وتقدم العلوم الكونية و الفلسفية إلا

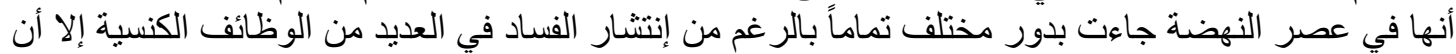

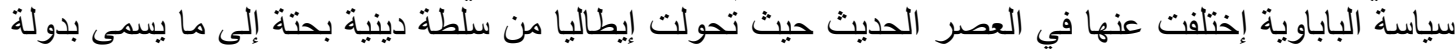

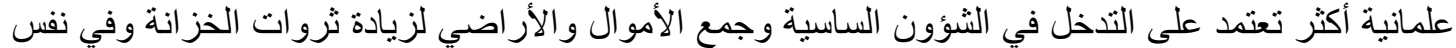

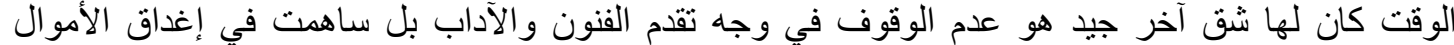

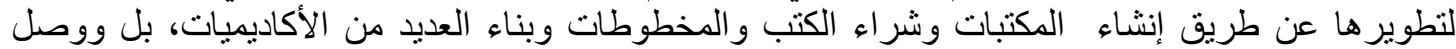

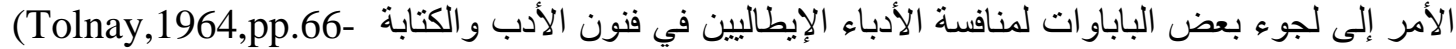

برزت النهضة الإيطالية في المدن ولكن لم تصل إلى نطاق القرى حيث أن الإنتعاش الإقتصادي وحرية الكتابة

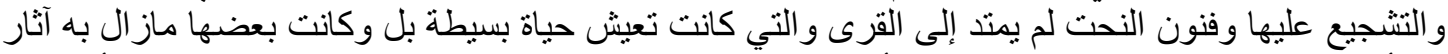
من أفكار العصور الوسطى عن ظو اهر التأمل والإعتقاد في السحر كما كانت سيطرة النبلاء في المدن أقل منها

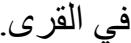

من المعروف أن عصر النهضة تمثل في تطور الفكر الأوروبي في العديد من المجالات أهمها الفنون والأداب لا

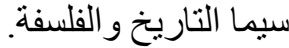

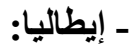

نشطت إيطاليا في عصر النهضة في عدة مجالات مثل الفنون والآداب من الفنون فن الرسم والنحت والتصوير وفي الآداب التاريخ و الفلسفة.

شاركت الدراسات التاريخية والبحث في الآثار القديمة الرومانية في إيطاليا دوراً كبير اً في تطور الفكر الأوروبي

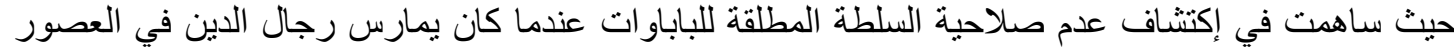

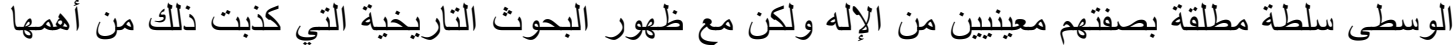
بحث جديد في النقد التاريخي أخرجه الإيطالي (لورنزو فاللي Lorenzo Valla ) أثبت فيه أن الوثيقة الخاصة

بالإمبر اطور قسطنطين المسماه (Donation de Constantin) كاذبة)(1)، هذه الوثيقة كانت تقر بتنازل

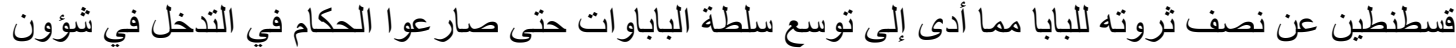
الحكم.

جاء الإهتمام بدر اسة الآثار الرومانية القديمة بعدما كانت مهملة خاصة من جانب النبلاء بل وفقد العديد منها جر اء التصرفات الخاطئة في نقلها.

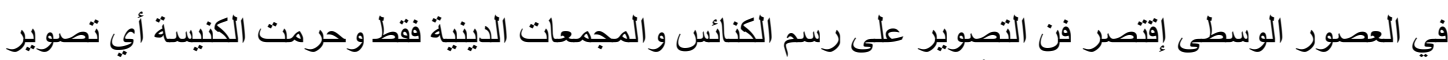

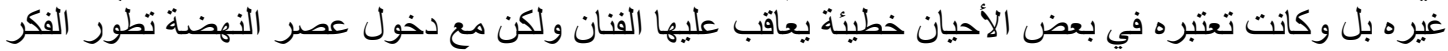

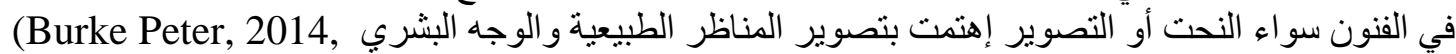

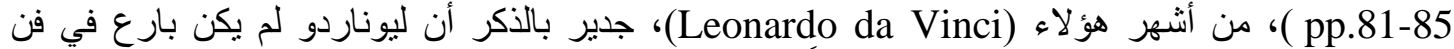
التصوير فحسب ولكنه عمل بدر اسة التشريح أيضاً. 


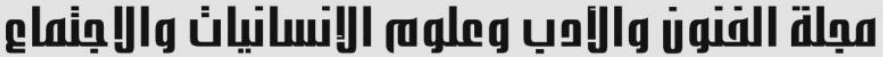

Journal of Arts, Literature, Humanities and Social Sciences www.jalhss.com

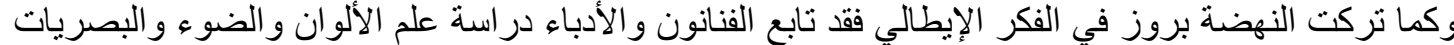

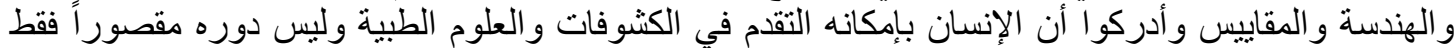
على العبادة والتأمل دون فائدة تذكر كما كان في السابق (Gene Bruckner,1983,pp.44-61)

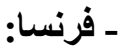

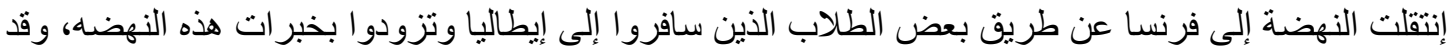

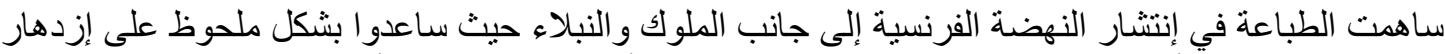

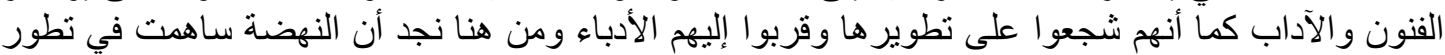

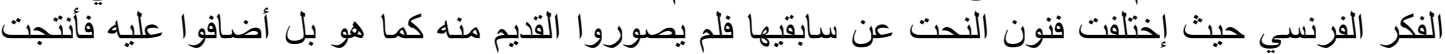
فنون حديثة تختلف عن إيطاليا التي إهتمت بتقليد النحت الروماني كما كان عليه دون إدخال العديد من التعديلات الفيه

كما ساعدت النهضة في فرنسا على نشوء مفسرين للمصطلحات القانونية (81-76-2001,pp.76).

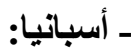

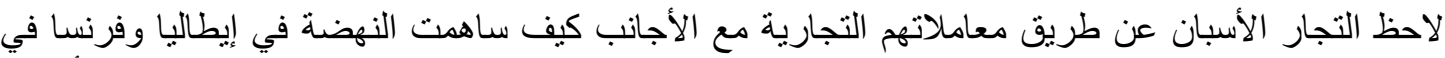

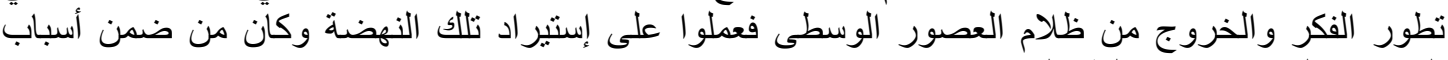
التشجيع عليها إضعاف سلطة النبلاء.

تمثلت بداية النهضة في إنشاء الأكاديميات الملكية الأسبانية ، بالإضافة إلى العديد من الثبان الأسبان الذين عادو ا

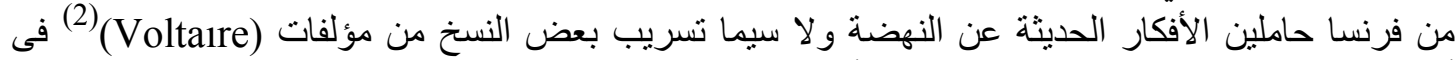

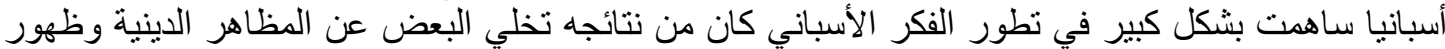

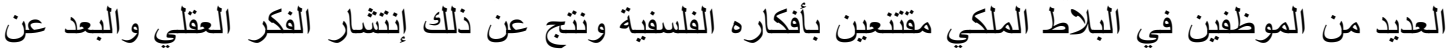
الدرسات الدينية داخل الكنيسة (117-110).

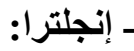

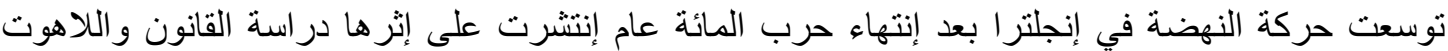

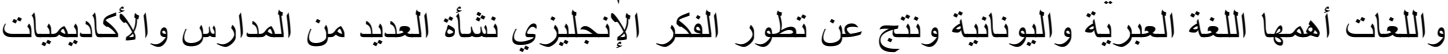

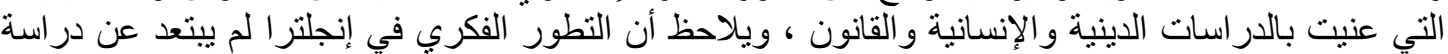

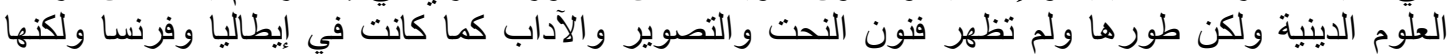

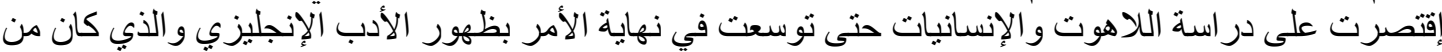

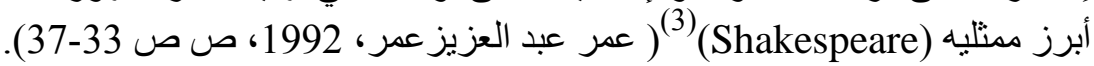

ـ الكثوف الجغرافية

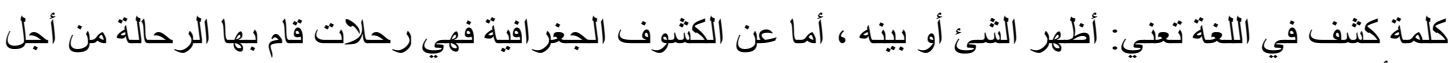

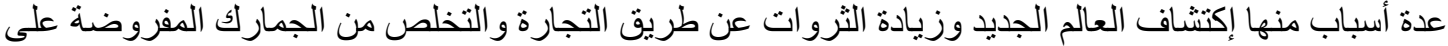

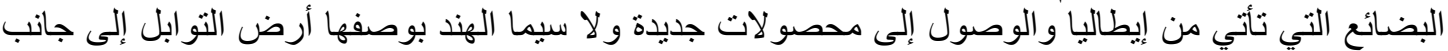

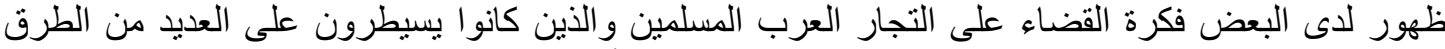

التجارية الهامة ويقوموا بدور الوسيط التجاري بين بلاد الثرق وأوروباء التربيا.

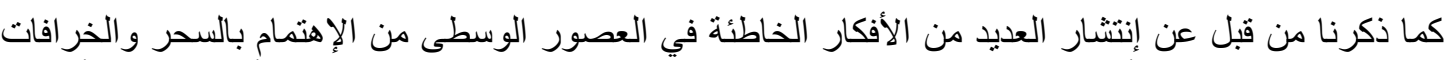

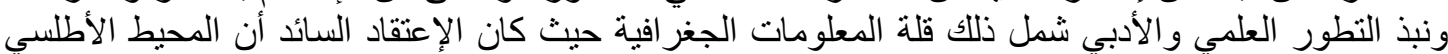
و البحار الجنوبية هي منطقة بعيدة نائية تسكنها الجن والثياطين والوحوش ولم تتعدى المعرفة خارج الإن نطاق التها 


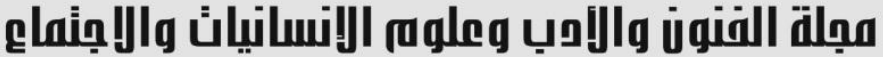

Journal of Arts, Literature, Humanities and Social Sciences www.jalhss.com

الأراضي الأوروبية أكثر من قارة أفريقيا والسواحل الثمالية والثمالية الغربية كما أن البحار تحتوي على صخور ضخمة تحطم السفن عندما تقترب منها.

وبالرغم من إنتشار تللك الأفكار على نطاق واسع إلا أنها إحتوت على جانب إيجابي إتجه نحوه محبي المغامرة

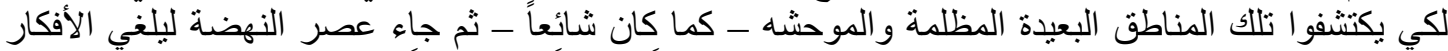

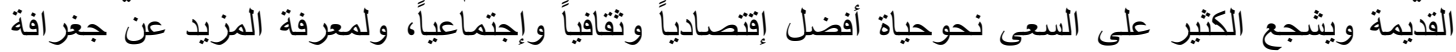

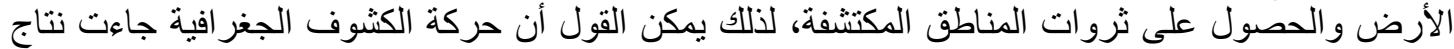
طبيعي لما خلفه عصر النهضة من تغيير الفكر الأوروبي وخروجه من العصور الوسطى (المرجع نفسه،

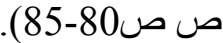

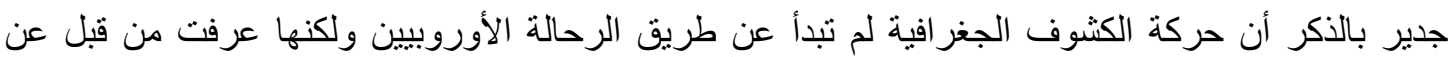

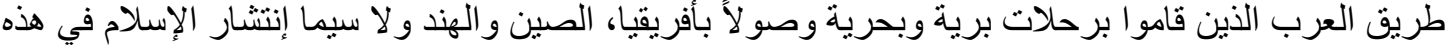
المناطق عن طريق حركة التجار العرب المسلمين.

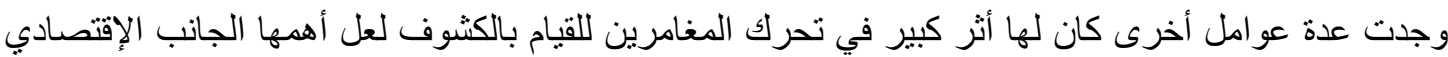

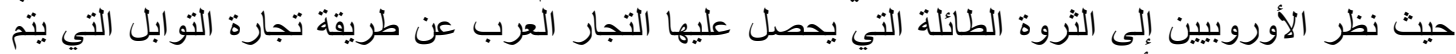

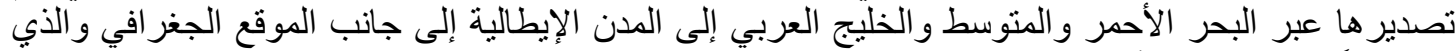

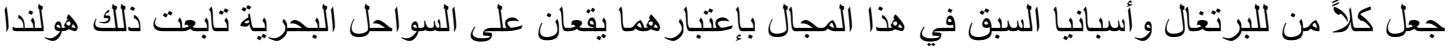

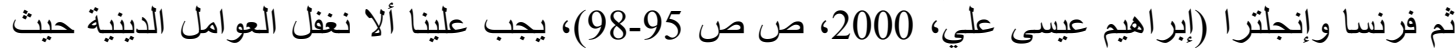

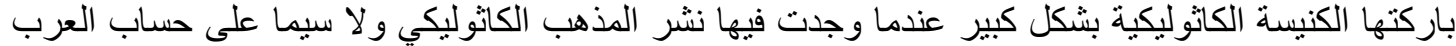

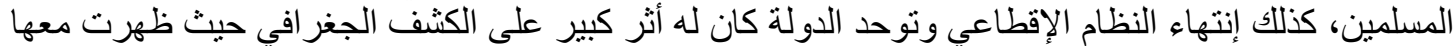

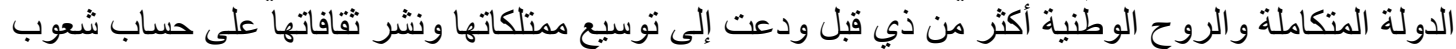
أخرى (الخالدي سعود الزينون، 2009).

فنجد أن البرتغال والتي كان لها السبق ظهرت كقوة بحرية منذ القرن الثالث عشر أنشأت أساطيل وأصبحت تشكل قوة بحرية في المحيط الأطلنطي.

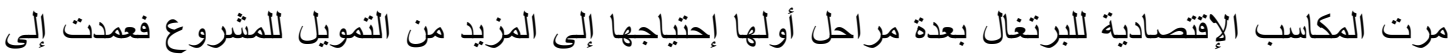

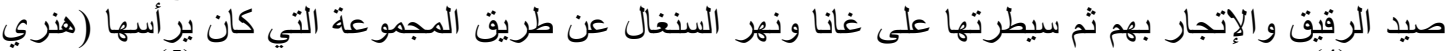

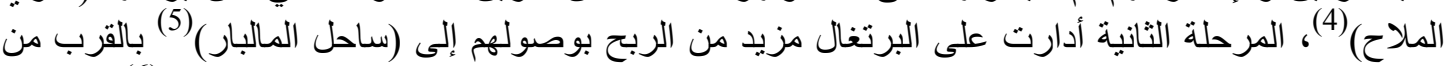

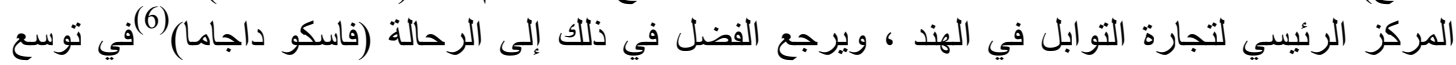

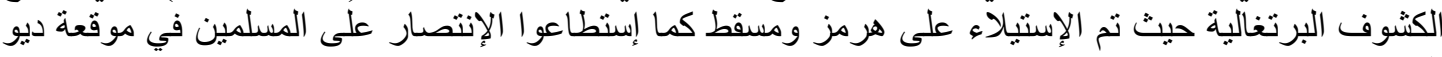
البحرية.

إستطاعت البرتغال من إنشاء محطات مسلحة تمون الأساطيل وتقوم بحر اسة الثو اطئ الهندية وذلك بغرض التوسع في تجارة التو ابل و التي تدير المزيد من الأرباح.

لكن بالرغم من الإنتعانش الإقتصادي الذي عاثنته البرتغال جر اء الكثوف الجغر افية إل أن داخل الإمبر اطورية

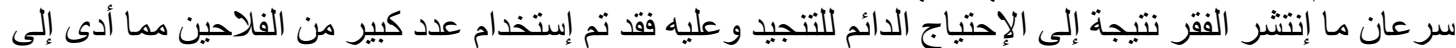

خلو الأر اضي الزر اعية وسوء الحالة الإقتصادية في الداخل (Russell, 1998, pp.92-98).

وعن أسبانيا فقد إتجهت إلى الكثف الجغر افي بنية مكاسب إقتصادية ودينية ، حيث أعطى الكثف الأسباني

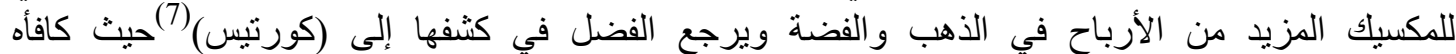
الإمبر اطور شارل الخامس بتوليه عليها. 


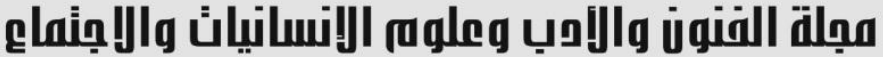

Journal of Arts, Literature, Humanities and Social Sciences

\section{www.jalhss.com}

توسعت الكثوفات الأسبانية لتصل إلى أمريكا الجنوبية بقيادة (كولومبوس) (8)، إمتدت حتى بيرو، كما وصلت

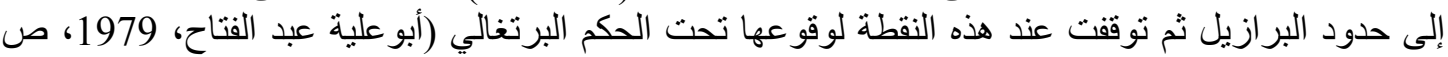

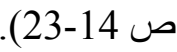

إعتمدت الكثوف الهولندية على الجانب الإقتصادي حيث ركزت كل الإهتمام عليه وذللك عن طريق (شركة الهند

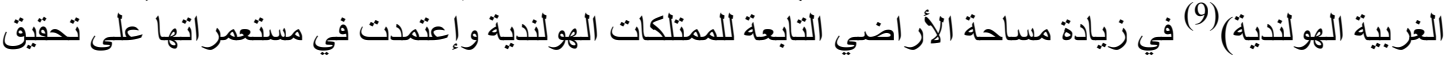

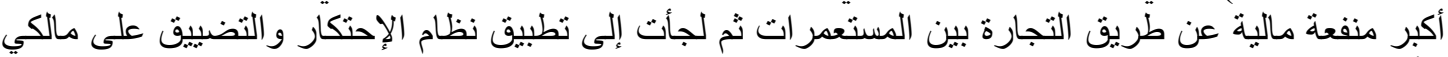

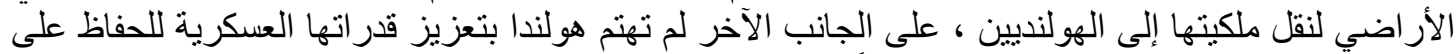

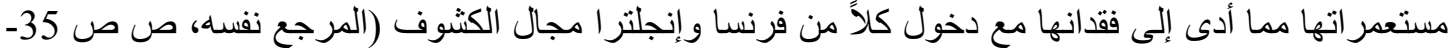

وبالرغم من دخول فرنسا و إنجلتر ا مجال الكثف الجغر افي متأخر اً مقارنة بالبرتغال و أسبانيا إلا أنهما إستطاعا

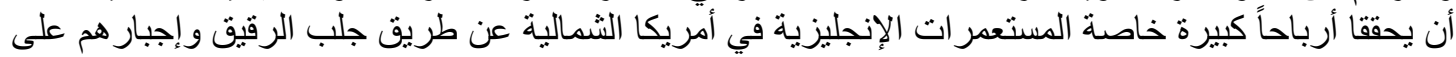
العمل الثاق في الزراعة والصناعة عقب إضطهادهم للهنود الحمر وإبادة معظمهم (- Hartig,1908, pp.92

إتجىت الكثوف الفرنسية نحو الهند و إستطاعت السيطرة على الثو اطئ من ناحية الثرق والغرب ساعدها ذلك

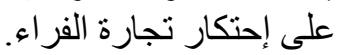

عند در اسة الجانب الديني للكثوف الجغر افية نجد وجود رغبة بعض الكثوف في التخلص من التجار المسلمين للإستيلاء على التجارة و التشو اطئ المملوكة لهم ، وقد شاركت في ذللك كلاً من البرتغال، أسبانيا وفرنسا.

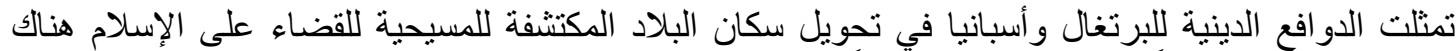

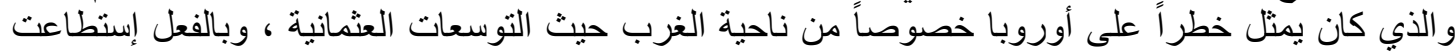

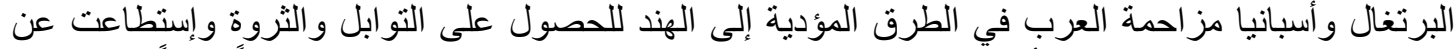

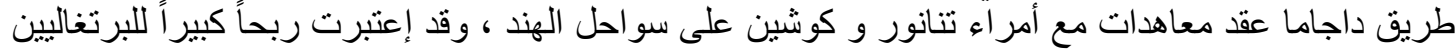

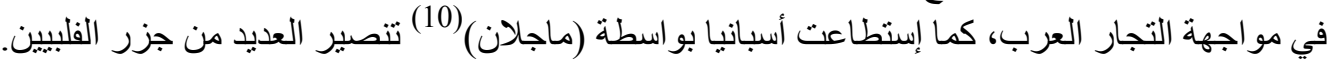

حتى وصلت إلى جزيرة ماكتان الإسلامية ولكنها باءت بالفثل (11) (Zaide,1994, pp.83-85).

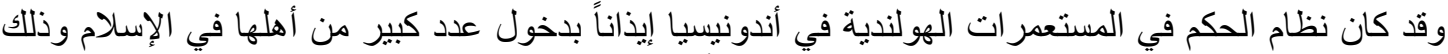

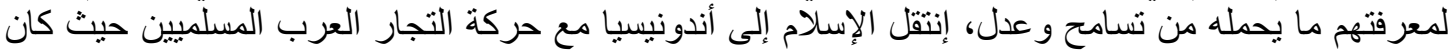

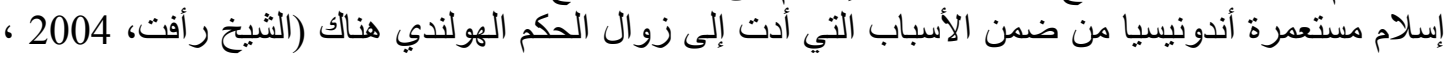

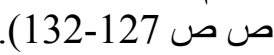

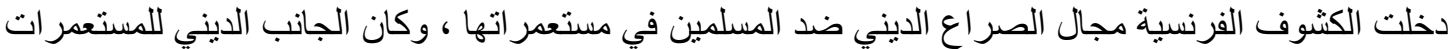

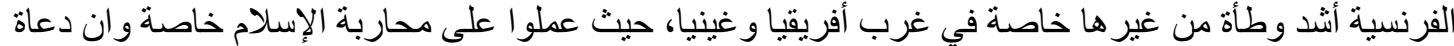

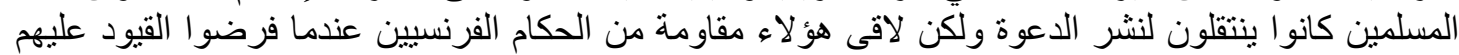

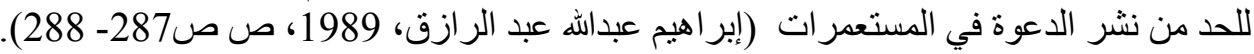

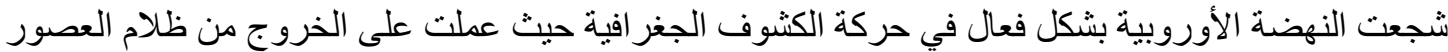

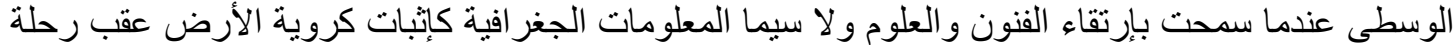
ماجلان، ونفي وجود وحوش أو جن يسكن البحار و المناطق البعيدة عن القارة الأوروبية ل... إلخ. وقد ساعد هذا بدوره على إنشاء السفن و إستخدام البوصلة و الإسطر لاب وتقدم حركة الملاحة التي شجعت على تطور ونجاح الكثف الجغر افي. 


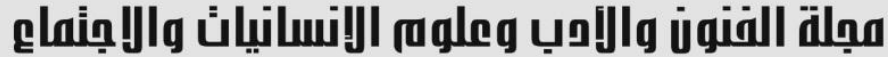

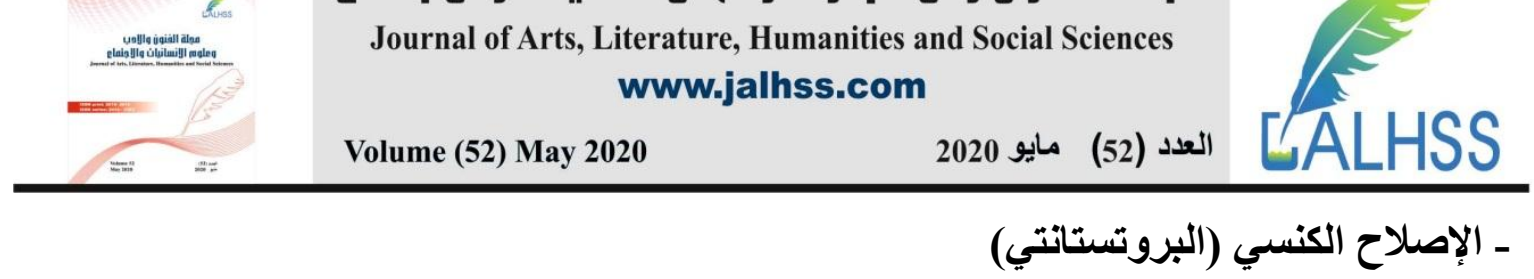

مع توسع الفكر الأورووبي في عصر النهضة بدأ في مقارنة بعض الأسباب التي كانت تؤثر عليه في الماضي

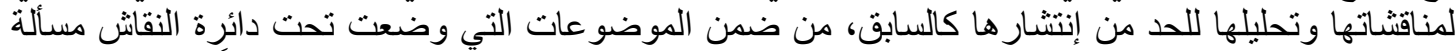

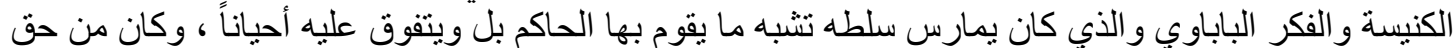
الكنيسة تجريم فكر معين و الحكم عليه بالإعدام أو السجن وأحياناً بغر امات مالية باهظة.

من هنا جاءت فكرة الإصلاح الديني للكنيسة الكاثوليكية حيث إعتبر من السمات التي تميز بها الفكر الأوروبي عقب عصر النهضة. كلمة إصلاح في اللغة تعني: التغيير الغير جذري في الثكل الإجتماعي أو النظم الإقتصادية أو سياسية دون

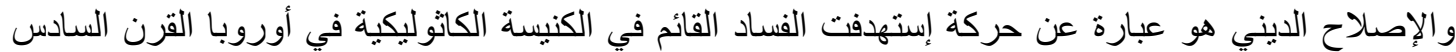

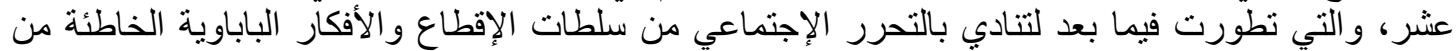

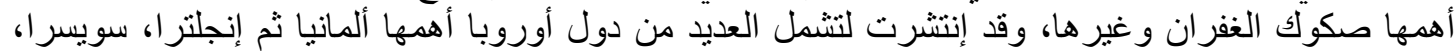

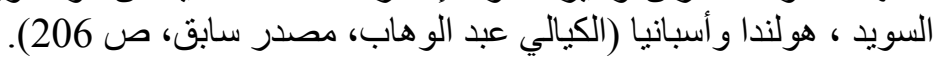

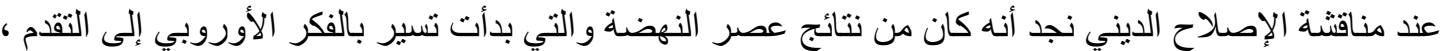

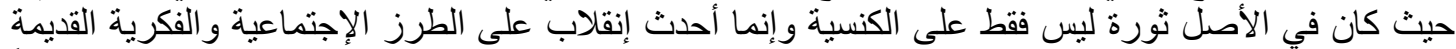

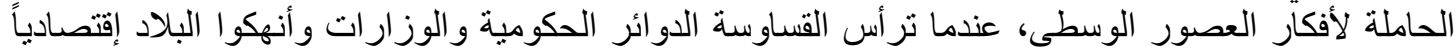

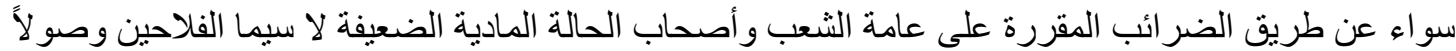

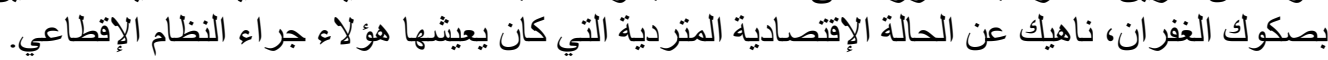

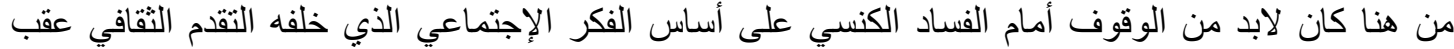

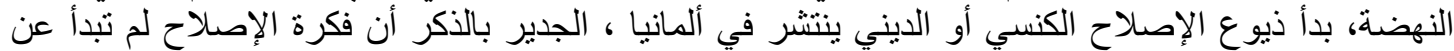

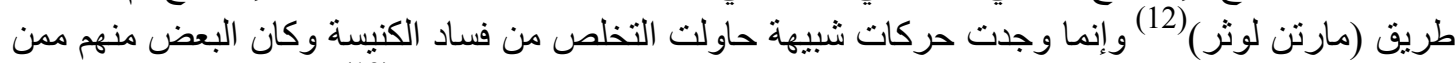

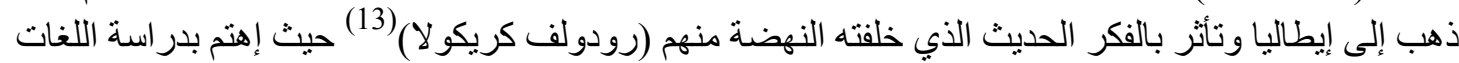

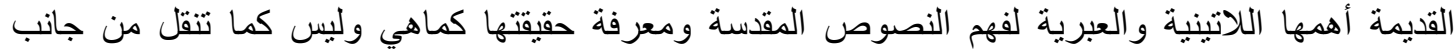

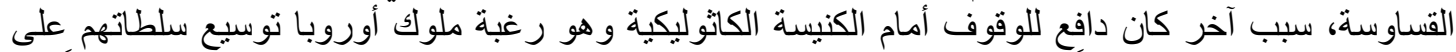

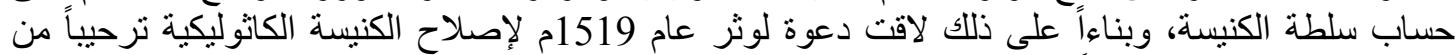

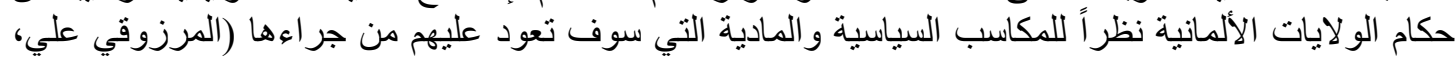
2006، ص ص ص الايت الأن 183-176).

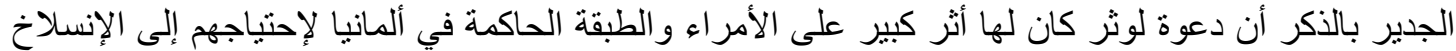

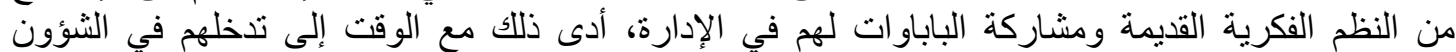

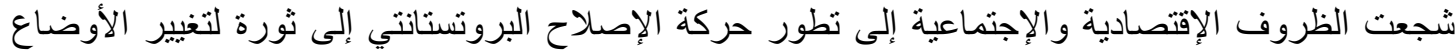

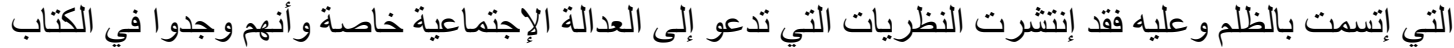

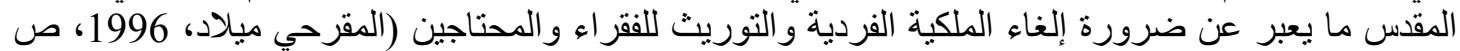

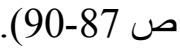

تم إنشاء إتحاد للفلاحين لمجابهة الظلم الواقع عليهم من زيادة الضرائب إلى جانب ضرائب (العشور

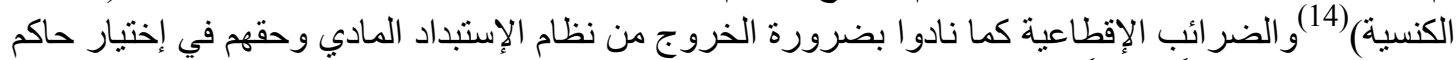

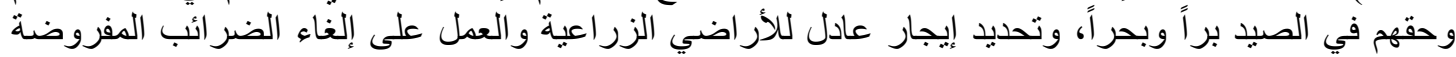




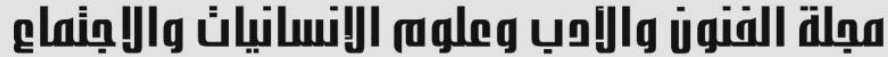

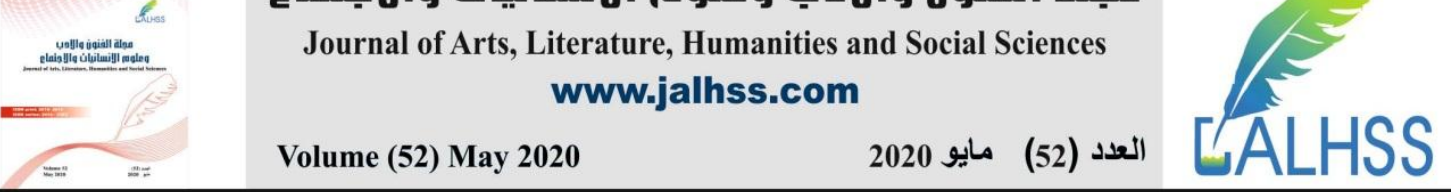

على الفقر اء، وبالر غم من فثل ثورة ومطالب الفلاحين إلا أنها فتحت الطريق إلى تطلعات جديدة لنظام إقتصادي

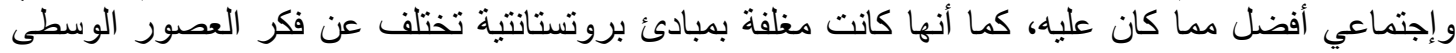
(الجمل شوقي، 2000م ، ص ص صل عل 47-52).

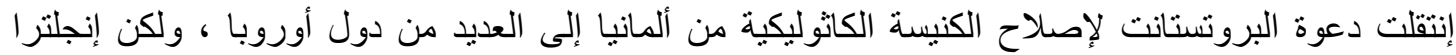

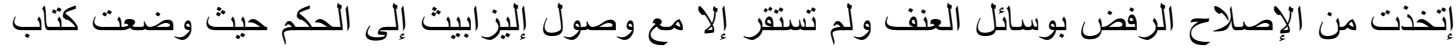

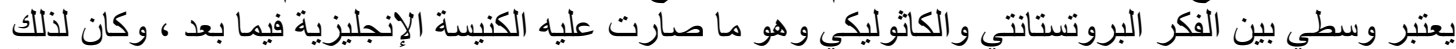

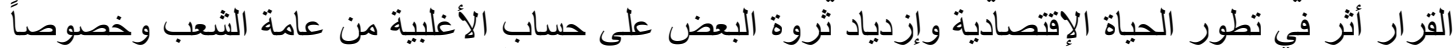

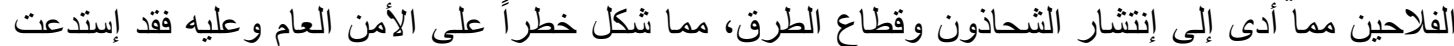
الحكومة إصدار عدة قو انين تساعد هؤ لاء على المعيشة وظلت تنفذ حتى منتصف القرن القرن التاسع عشر. نجد أن النظام الإقتصادي المستقر في هذه الفترى أدى إلى تطور الفكر الأدبي الإنجليزي فظهر الكثير من الأدباء

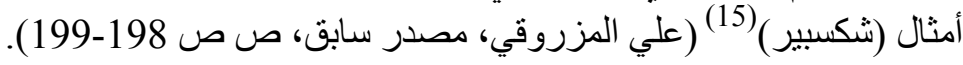

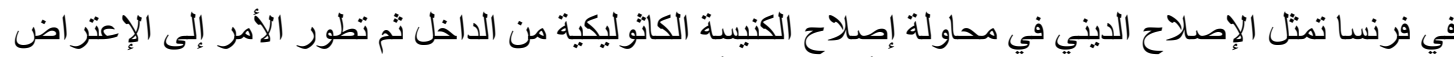

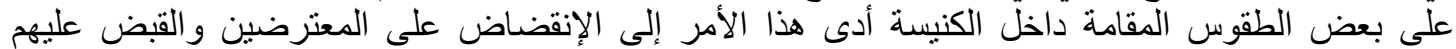
و إتهامهم بالهرطقة ، و إنتهى الوضع بالقبض عليهم وتعذيههم ثم قتلكم (Arthur Tilley,1919,pp.9-11)، في الإني

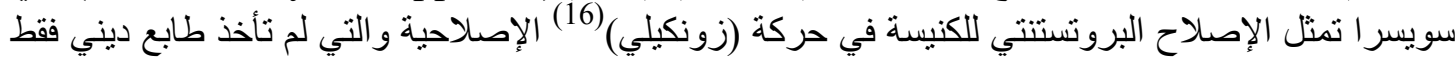

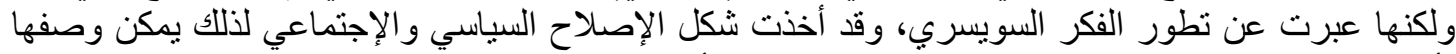

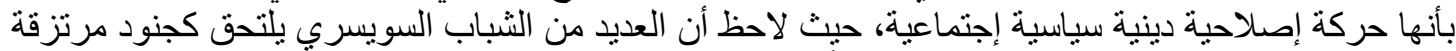

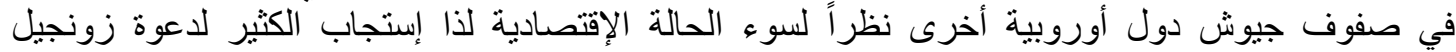

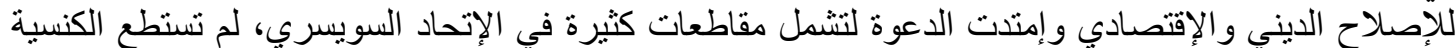

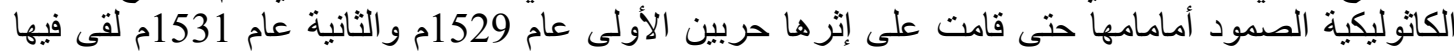

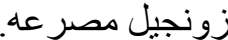

بالرغم من فقدان زونجيل إلا أنه عقد صلح كان له أثر في تغيير فكر الإمبراطورية الرومانية المقدسة بعد ما

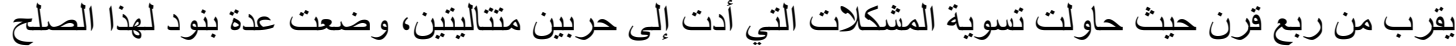

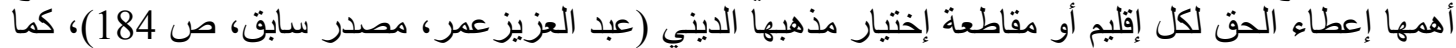

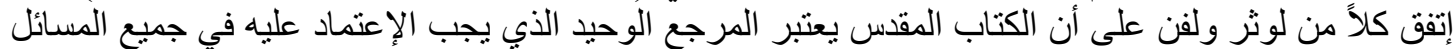
الدينية ، هذه الفكرة كانت بالطبع ضد صلن صكوك الغفران و التي كانت من أسباب الفساد الكنسي.

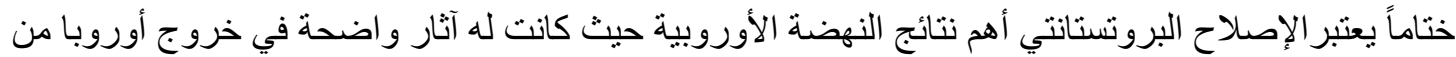

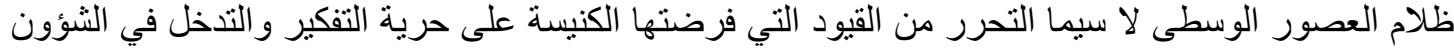

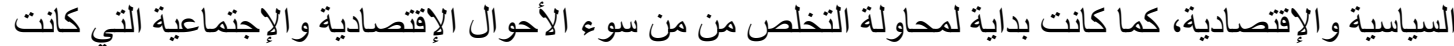
سائدة جر اء فرض الضر ائب الباهظة سو اء من قبل الكنيسة - بما فيها صكوك الأك الغفران - أو السلطة المدنية.

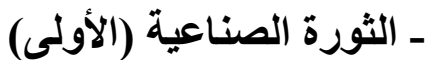

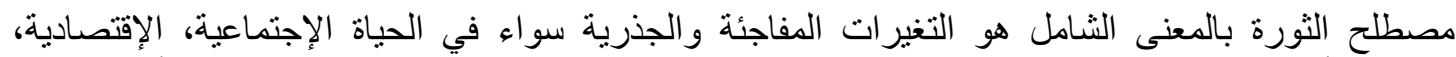

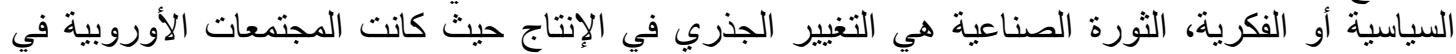

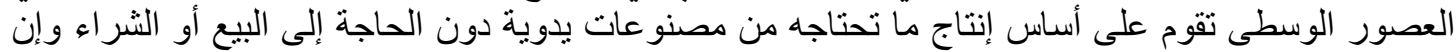

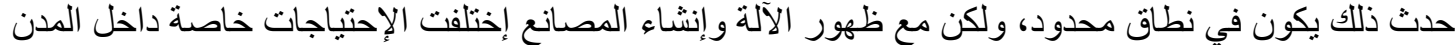

و هو التغيير الذي حدث في نمط الحياة أحدثثه الثورة الصناعية (الكيالي عبد الوهاب، مصدر سابق، ص الإن 903).

بدأت الثورة الصناعية الأولى عام1760م (17)، حيث كانت نقطة تحول في تاريخ العالم ومثلما كان السبق لإيطاليا في النهضة كانت إنجلتر ا صاحبة الخطوة الأولى للثورة الصناعية. 


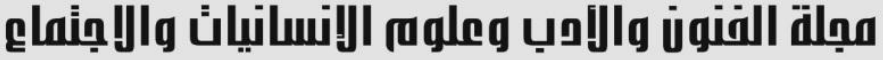

Journal of Arts, Literature, Humanities and Social Sciences

\section{www.jalhss.com}

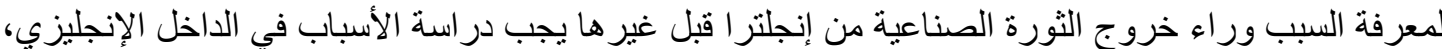

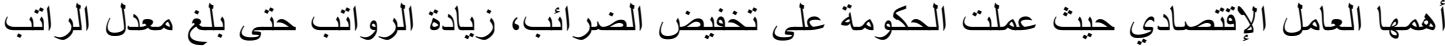

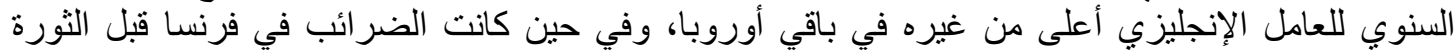

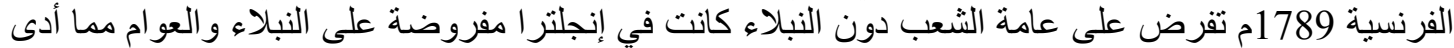
إلى نمو الحالة الإجتماعية و الإقتصادية للاولة والثة والأفراد على حد سواء.

إذ نظرنا إلى الأجور في إنجلتر ا مقارنة بنظير اتها في أوروبا نجد أن دخل الفرد أعلى بنسبة 50\% إلى 60\% مما سمح للأفر اد تناول اللحوم و الخبز بشكل يومي.

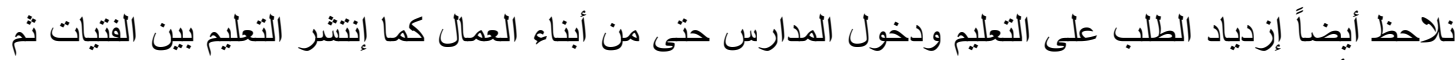

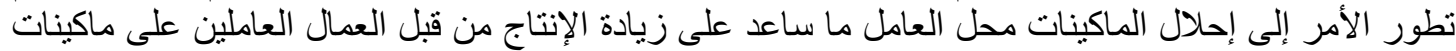

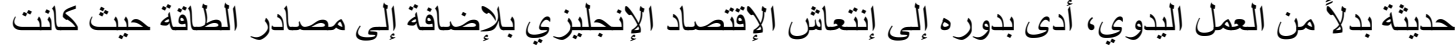
إنجلتر ا تمتلك العديد من مناجم الفحم والذي ساعد على الذي خفض التكلفة على وسائل الطاقة.

انفقت إنجلترا أمولاً طائلة على صناعة الماكينات والبحث العلمي لتطوير ها أدى إلى إزدياد رأس المال في

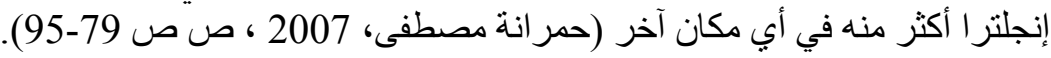

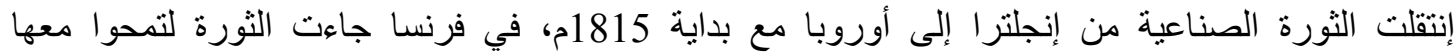

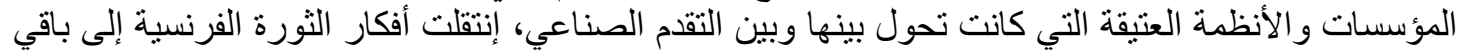

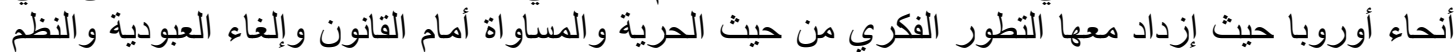

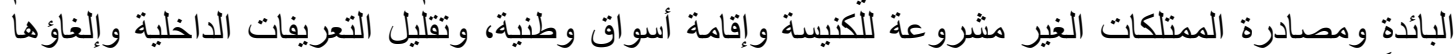

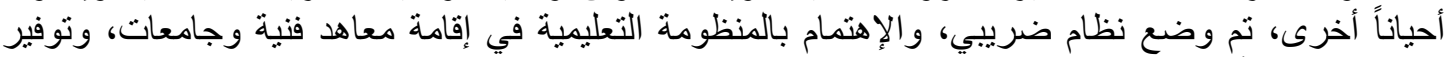
الدعم المادي للأبحاث العلمية و الجمعيات النقابية.

أما عن ألمانيا فكانت مثالاً جيداً في تطور الفكري للسير نحو الثورة الصناعية ومحاولاتها اللحاق بالركب إلتباء

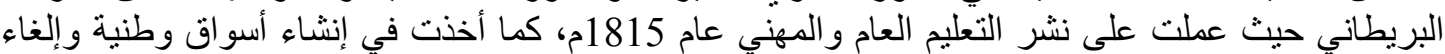

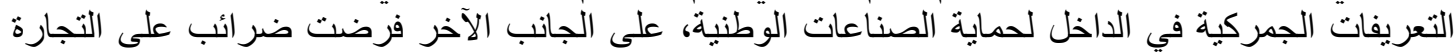

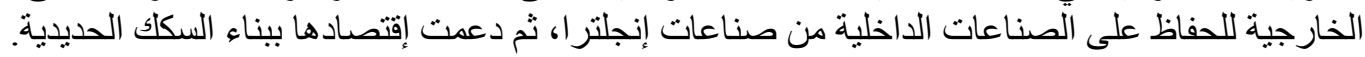

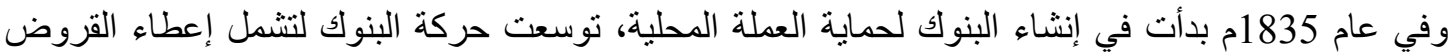

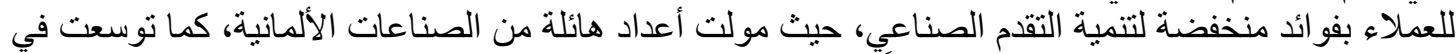

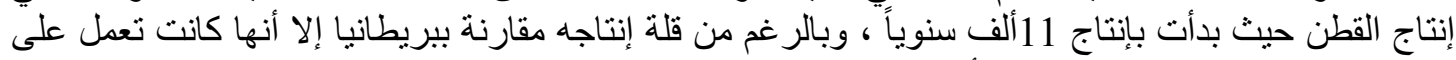
زيادته في حين كانت تنتج فرنسا 54 ألف طن سنو

الخاتمة

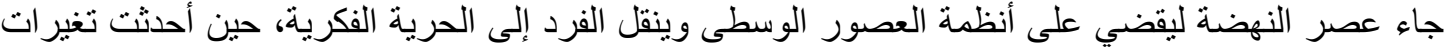

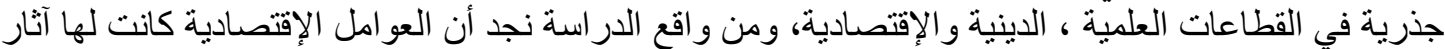

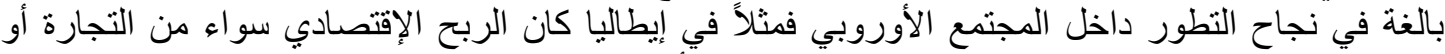

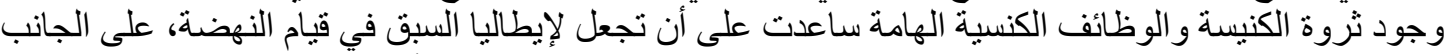

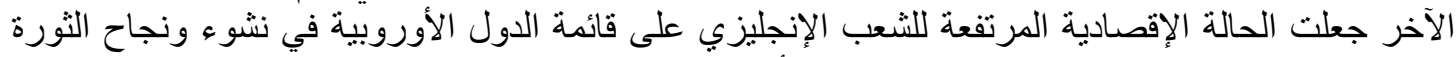

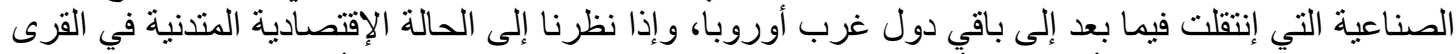

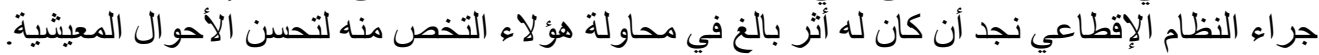




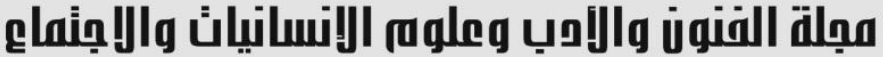

Journal of Arts, Literature, Humanities and Social Sciences www.jalhss.com

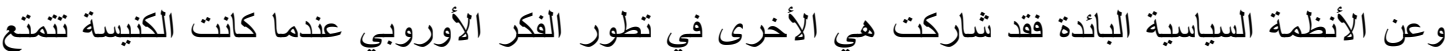

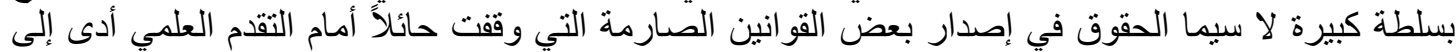
ضرورة إحداث إصلاح للفساد في الداخل و الذي تمثل في الإصلاح البروتستانتي.

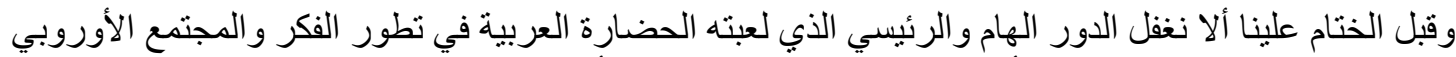

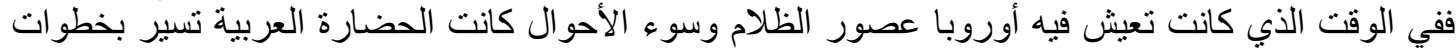

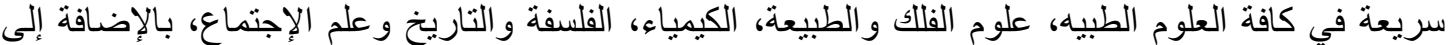

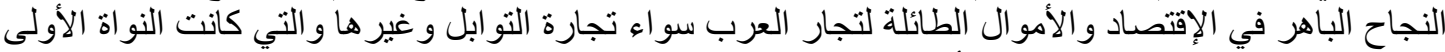
التي نقلها عنهم آلبحارة والمغامرين الأوروبيين الإكتشاف العالمالم الجديد.

1. وثثقة مزورة بإسم قسطنطين الأكبر وإنقسمت الوثيقة إلى شقين الأول إحتوى على التعليم الذي تلقاه

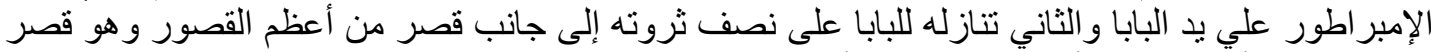

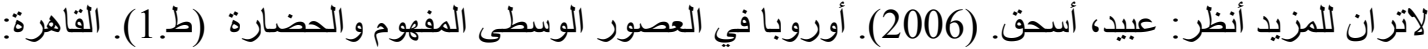

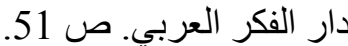
2. فر انسوا ماري الثهير بإسم فولتير هو فيلسوف وكاتب فرنسي إثتهرت كتاباته بالدفاع عن الحياة المدنية

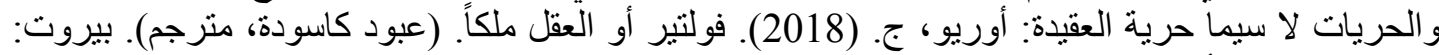

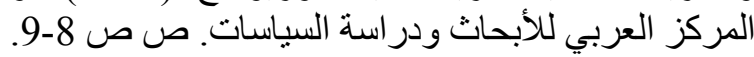

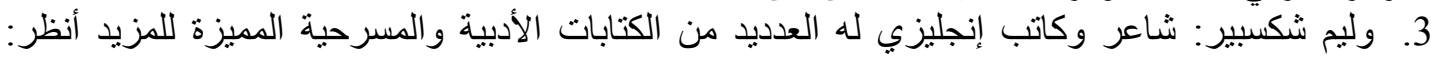
Ackroyd, P. (2006). Shakespeare the biography (1st. ed.). London. Anchor Books. p.7.

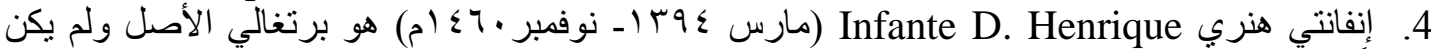

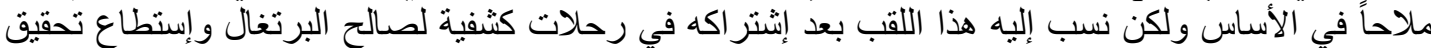

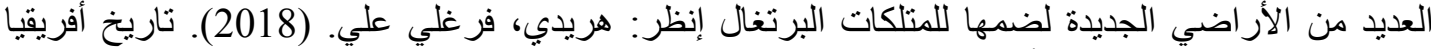

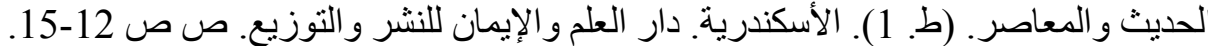

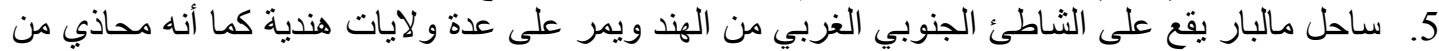

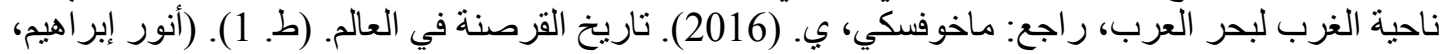

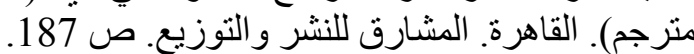

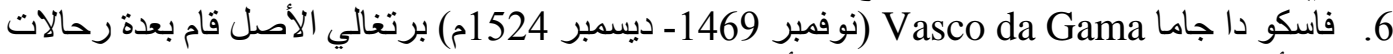

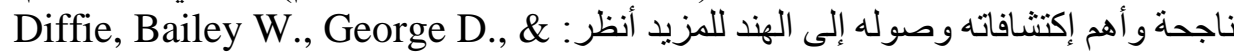
Winius.(1977). Foundations of the Portuguese Empire 1415-1580.(vol. 1). Minnesota:University of Minnesota Press. p. 12.

7. هرنان كورتنيس Hernán Cortés (1485 - 1547م) ولد في أسبانيا وله الفضل في توسع ثروة أسبانيا

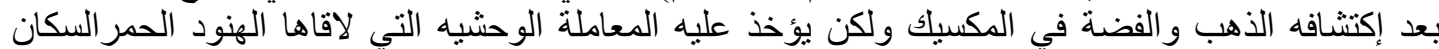

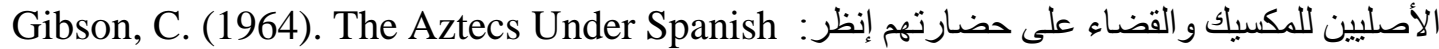

Rule. California: Stanford University Press. pp. 20-25. 8. كريستوفر كولومبوس Christophorus Columbus رحالة إيطالي الأصل كان ينسب إليه إكتشاف

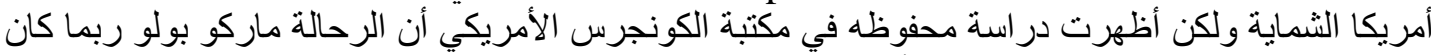

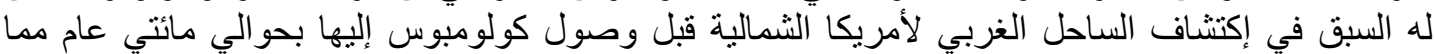




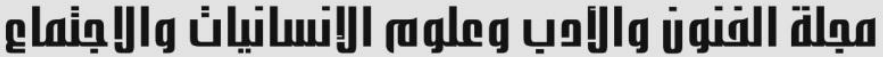

Journal of Arts, Literature, Humanities and Social Sciences www.jalhss.com

يوضح أنه ليس المكتشف الأول لأمريكا الثمالية أنظر: عبود، مارون. (1910). كريستوف كولومب. القاهرة:

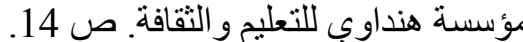

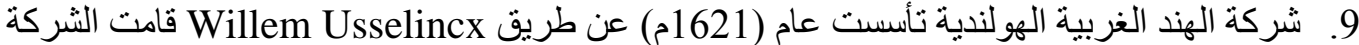

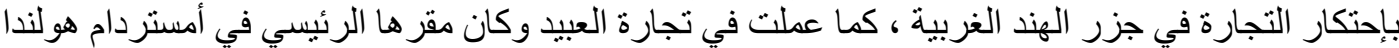

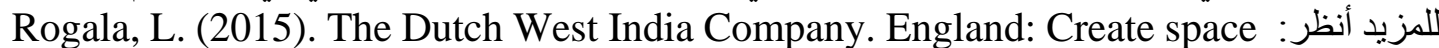
publishing. P. 7.

10. الكثوف الأسبانية وإستطاع إكتشاف عدة جزر لصالح أسبانيا كان من الجزر في بحر الصبين حيث أطلق عليها

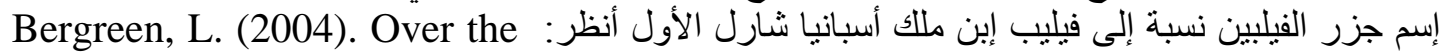
Edge of the World: Magellan's Terrifying Circumnavigation of the Globe. New York: Perennial / HarperCollins. pp. 21-3.

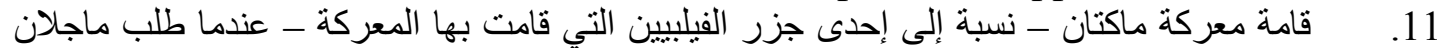

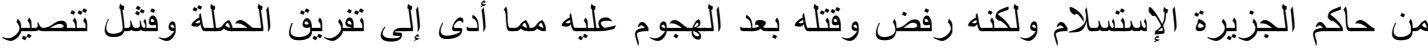

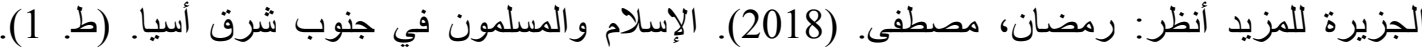

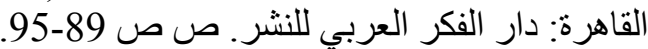
12.

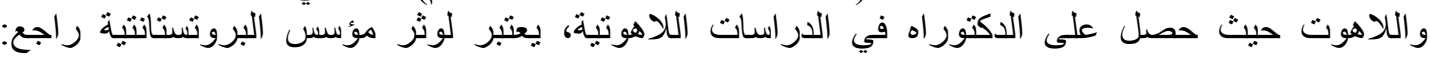

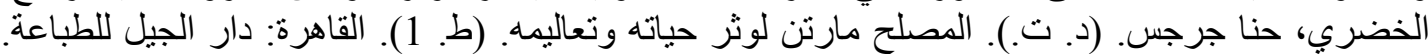

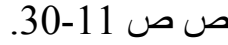

رودولف كريكو لا Rudolf Krikula: ألماني الأصل ويعتبر من رجال النهضة أنظر : Baum, Jo .13 M. (2018). The Paradox of Religious Belief and Practice in Germany. Illinois: University of Illinois Press. pp. 15-17.

14. ضر ائب العشور الكنسية: إحدى الضر ائب التي كانت تفرضها الكنيسة على الفلاحين بمقدار عشر ما

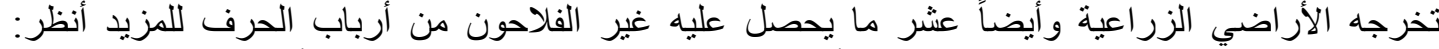

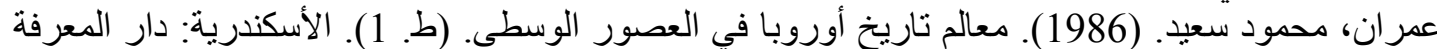

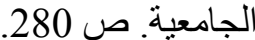

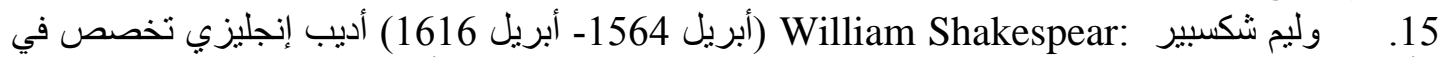

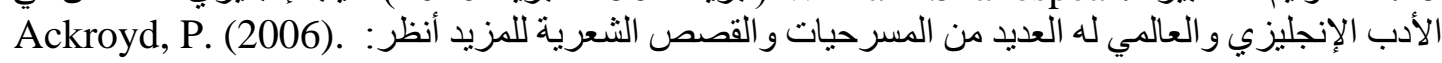

Shakespeare The Biography. Norwell: Anchor press. pp. 15-17.

16. هولدريخ زوينكلي Ulrich Zwingli (يناير 1484- أكتوبر 1531م) ولد في سويسرا، بعد الإنتهاء

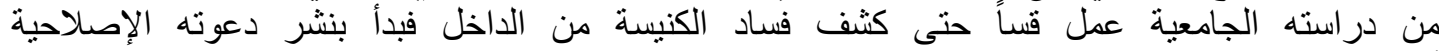
Oechsli, W. (1922). History of Switzerland 1499 -1914. Cambridge: انظر :

Cambridge University press. pp. 66-70.

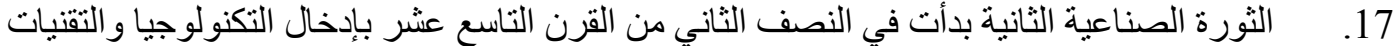

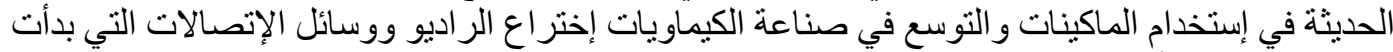

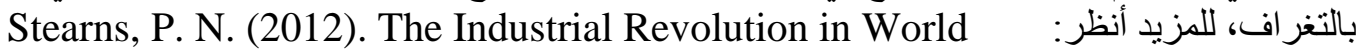
History. Colorado: Westview Press. pp. 21-26. 


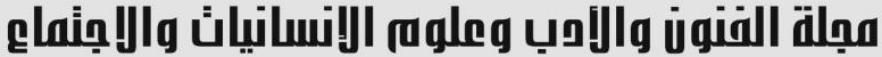

Journal of Arts, Literature, Humanities and Social Sciences www.jalhss.com

(1) إبراهير، عبداله عبد الرازق. (1989). الدسلمون والإستعمار الأوروبي لأفريقيا (ط. 1). الكويت: عالم (المعرفة للنشر.

(2) إبر اهيم، عيسى علي (2000). الفكر الجغرافي والكشوف الجغر/فية. الأسكندرية: دار المعرفة الجامعية.

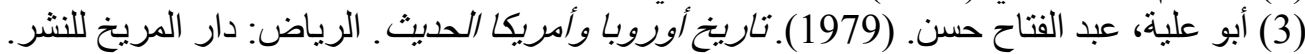

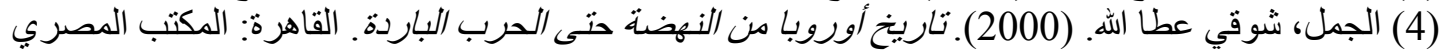

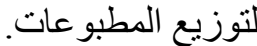
(5) برون، ج. (2006). تاريخ أوروبا الحديث (ط. 1). (علي المرزوقي، مترجم). عمان: الأهلية للنشر

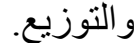

(6) الثيخ، رأفت غنيمي، وعبد العزيز، محمد رأفت، و هدهود، ناجي. (2004). تاريخ أسبا الحدبث

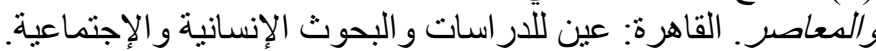

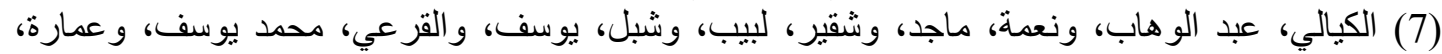

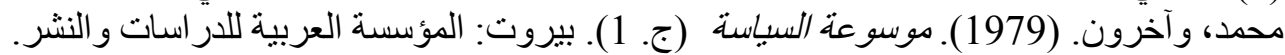

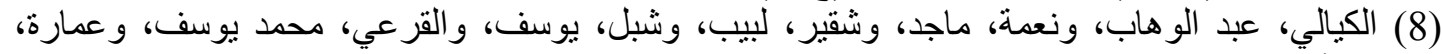

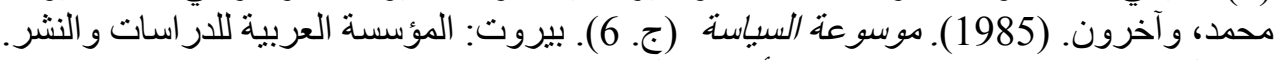

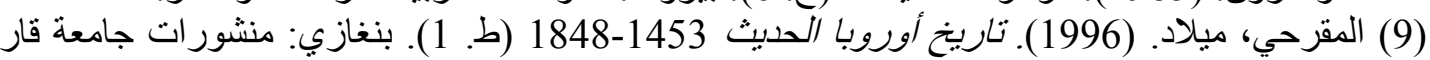
يونس. (10) عمر، عبد العزيزعمر. (1992). التاريخ الأوروبي والأمريكي الحديث. الأسكندرية: دار المعرفة

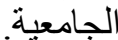

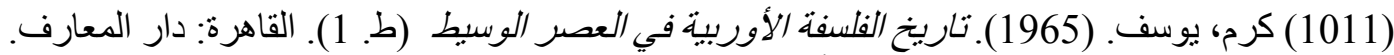

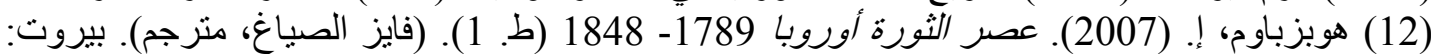
مركز دراسات الوحدة العربية. ثانياً - المراجع الأجنبية

(1) Bruckner, G. (1983). Renaissance Italy (1st. ed.). California: University of california press.

(2) Durant, W. (1980). Story of Civilization (1st. ed.). New York: MJF Books press.

(3) Hartig, O. (1908). "John \& Sebastian Cabot." The Catholic Encyclopedia (Vol. 3). New York: Bert appleton company press

(4) Peter, B. (2014). The Itakian Renaissance, Culture and society. New Jersey: Princeton University press.

(5) Russell, W., A.J.R. (1998). The portugues Empire 1415-1825. Maryland: John Hopkins University press..

(6) Simonin, M. (2001). Dictionnaire des latters françaises (Vol. 16). Paris: Éditions Fayard.

(7) Tilley, A. (1919). The French Wars of Religion (1st. ed.). London: Sagwan Press.

(8) Tolnay, C. (1964). The Art and Thoughe of Michelangelo (Vol. 5). New York: Pantheon Books.

(9) Zaide, S. M. (1994). The Philippines A Unique Nation. Philippines: All nations Publishing Co.
ثالثاً ــ الدوريات
الخالدي، سعود الزينون. (2009، 26، إبريل). المقاومة الخليجية ضد التتصير. مجلة الواحة، (8). 


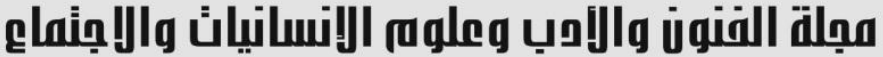

Journal of Arts, Literature, Humanities and Social Sciences

www.jalhss.com

Volume (52) May 2020

العدد (52) مايو 2020

\section{References}

(1) Ibrahim, Abdullah Abdul Razek. (1989). Muslims and European colonization of Africa (1st. ed.). Kuwait: Knowledge World for Publishing.

(2) Ibrahim, Issa Ali (2000). Geographical thought and geographical statements. Alexandria: House of University Knowledge.

(3) Abu Alia., Abdel-Fattah Hassan. (1979). Modern History of Europe and America. Riyadh: Mars Publishing House.

(4) AL Gamal, Shawky Atallah. (2000). Europe's history from the Renaissance to the Cold War. Cairo: The Egyptian Publications Office.

(5) Pron, G. (2006). Modern History of Europe (1st. ed.). (Ali Al Marzouqi, translator). Amman: Al Ahlia Publishing and Distribution.

(6) Sheikh, Raafat Ghanimi., Abdel Aziz, Mohamed Raafat., \& Hadhoud, Nagy. (2004). Modern and contemporary history of Asia. Cairo: appointed to human and Social Studies and research.

(7) Al-Kayali, Abdel-Wahab., Neama, Majed., Shugair, Labib., Shebl, Youssef., AlQarai, Mohamed Youssef., Amara, Mohamed., \& others. (1979). Encyclopedia of Politics (Vol. 1). Beirut: Arab Institution for Studies and Publishing.

(8) Al-Kayali, Abdel-Wahab., Neama, Majed., Shugair, Labib., Shebl, Youssef., AlQarai, Mohamed Youssef., Amara, Mohamed., \& others. (1985). Encyclopedia of Politics (Vol. 6). Beirut: Arab Institution for Studies and Publishing.

(9) Megrahi, Milad. (1996). Modern History of Europe 1453-1848 (1st. ed.). Benghazi: Publications of Qar Younis University.

(10) Omar, Abdel Aziz Omar. (1992). Modern European and American history. Alexandria: House of University Knowledge.

(11) Karam, Youssef. (1965). History of European Philosophy in the Middle Age (1st. ed.). Cairo: Dar Al-Maaref.

(12) Hobsbaum, E. (2007). The Era of the Revolution, Europe 1789-1848 (1st. ed.). (Fayez Al-Sayagh, translator). Beirut: Center for Arab Unity Studies.

(13) Al-Khalidi, Saud Al-Zaitoun. (2009, 26, April). Gulf resistance against Christianization. Oasis Magazine, (8). 